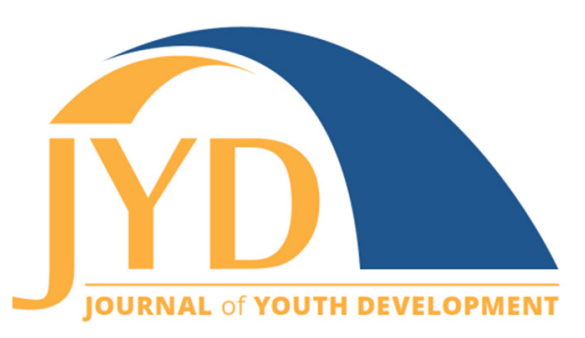

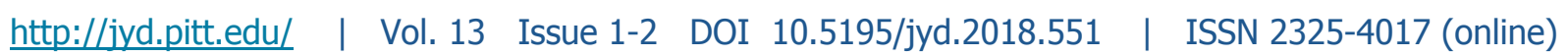

\title{
Positive Youth Development at Camps for Youth with Chronic Illness: A Systematic Review of the Literature
}

\author{
Mya DeBoer Sendak
}

Duke University, Department of Pediatrics

mya.sendak@duke.edu

\section{Clarissa Schilstra}

Duke University School of Medicine, Department of Psychiatry and Behavioral Sciences clarissa.schilstra@duke.edu

Eitan Tye

Duke University School of Medicine, Department of Psychiatry and Behavioral Sciences eitan.tye@duke.edu

\section{Samuel Brotkin}

Duke University, Department of Psychology and Neuroscience

samuel.brotkin@duke.edu

\section{Gary Maslow}

Duke University School of Medicine, Department of Psychiatry and Behavioral Sciences gary.maslow@duke.edu

\begin{abstract}
This study aimed to systematically review all the literature on camps for youth with childhood onset chronic illness (COCI) utilizing the Positive Youth Development (PYD) framework to assess camp processes and psychosocial outcomes. This paper describes a unique dataset of 425 included studies published over the last 70 years and gives a broad overview of camp demographics, processes that align with PYD's Big 3 (sustained adult-youth relationships, skill-building, and youth leadership) and measured outcomes that align with the PYD's 5 Cs (Competence, Confidence, Character, Social Connectedness, and Compassion). Among the included studies, $36 \%$ included diabetes camps, $15 \%$ included camps accepting multiple illnesses, $12 \%$ included cancer camps, and $11 \%$ included asthma camps. The majority of participants were under the age of 16. While no study explicitly used the PYD approach, over 90\% of studies described camps that deployed both active leadership and sustained positive relationships, while only 59\% of studies described camps providing the opportunity to learn life skills. Although no study utilized the PYD 5 Cs framework for outcome measurement, $47 \%$ addressed outcomes related to Competence, $44 \%$ addressed Confidence, 33\% addressed Connection, 4\% addressed Compassion, and $2 \%$ addressed Character. This review highlights opportunities for camp leadership to align their programming with the PYD framework, to incorporate older adolescents and young adults and,
\end{abstract}

(cc) $\mathbf{E Y}$ New articles in this journal are licensed under a Creative Commons Attribution 4.0 License. This journal is published by the University Library System, University of Pittsburgh and is cosponsored by the University of Pittsburgh Press. The Journal of Youth Development is the official peer-reviewed publication of the National Association of Extension 4-H Agents and the National AfterSchool Association. 
Journal of Youth Development | http://jyd.pitt.edu/ | Vol. 13 Issue 1-2 DOI 10.5195/jyd.2018.551

PYD at Camps for Youth with Chronic Illness

ultimately, to improve positive adult outcomes for youth with COCI. It provides a starting point for future research evaluating illness-specific camps using a PYD approach.

Key words: camp, youth with childhood onset chronic illness, positive youth development

\section{Background}

\section{History of Camps}

Organized camping programs for youth in the United States began in the late 1800s, with camps that aimed to engage children in outdoor recreational activities. By the early $1900 \mathrm{~s}$, camps began incorporating intentional learning, specifically related to character development. During that time, the first physical illness-specific camps were offering opportunities for often isolated youth with physical childhood onset chronic illnesses (COCI) or disabilities to engage in social activities in non-medical environments, while still receiving adequate medical supervision (Ramsing, 2007). The medical professionals and advocates who founded these camps implemented intuitive programming based on common practice with the broad goal of improving the lives of children with COCI (McAuliffe-Fogarty, Ramsing, \& Hill, 2007).

Over the $20^{\text {th }}$ century, as medical and technological advancements increased the life span of children with various diseases, the number and types of illness-specific camps has expanded proportionally. Now camps exist for children with a wide range of physical conditions such as asthma, cancer, diabetes, HIV, inflammatory bowel disease, musculoskeletal diseases, skin diseases, and many more. The spread and success of these camps is a testament to their value; however, studying measurable outcomes to characterize that value continues to challenge the field.

\section{Current State of Camp Research}

In the past decade, a significant increase has been seen in studies evaluating medical specialty camps in order to understand the age- and illness-specific needs of campers and to inform the broader community of camp's impact on youth with COCI. A major review of camp literature published in 2005 examined 18 studies that evaluated a variety of types of illness-specific camps (Epstein, Stinson, \& Stevens). The review evaluated both psychological and physiological outcomes, including coping strategies, anxiety, attitude, self-concept, locus of control, knowledge of illness, and disease management, and found that improvements in health-related quality of life for children attending these camps were mixed across studies (Epstein et al., 


\section{PYD at Camps for Youth with Chronic Illness}

2005). Additional literature reviews of illness-specific camps for children with type 1 diabetes and children with burn injuries found the study designs made it difficult to fully describe the outcomes associated with camp beyond the overall finding that camps were safe and that potential benefits existed related to medical outcomes, adherence, and psychosocial adjustment (Maslow \& Lobato, 2009; 2010).

A more recent systematic review on camps for children with COCI found results similar to the review by Epstein and colleagues (Moola, Faulkner, White, \& Kirsh, 2014). Despite methodological limitations to the reviewed literature and a lack of long-term impact, the researchers concluded that participation in camp resulted in some short-term psychosocial benefits for children with a variety of chronic illnesses (Moola et al., 2014). These reviews focused on immediate and measurable psychosocial outcomes of camp participation and did not assess camp structure or programming described in the literature. Moola et al. (2014) found that camp studies were rarely informed by theoretical models, and to date no reviews have assessed for theoretical models informing camp programming. In this article, we assessed the medical specialty camp literature for camp processes and outcomes that are consistent with the evidence-based theoretical model of positive youth development (Eccles \& Gootman, 2002). A review of camps themselves, using the literature, may elucidate the gap between the limited short-term psychosocial benefits and the overwhelmingly positive qualitative data and participant feedback documented in the literature (Moola et al., 2014).

\section{Positive Youth Development Framework}

The Positive Youth Development (PYD) framework has shown success in informing the development of programs and interventions for at-risk youth (Eccles \& Gootman, 2002). PYD focuses on the development of strengths in youth to encourage positive adult outcomes, in contrast to previous interventional and research frameworks that focused solely on riskprevention to avoid negative adult outcomes (Lerner et al., 2009). According to the model (Lerner, 2004), three characteristics of positive youth development programs, known as the "Big 3," lead to positive outcomes for youth participants: the program involves sustained relationships between youth and adults, the program involves youth learning some form of life skill, and the program involves youth actively in participation and/or leadership. Programs that incorporate these Big 3 characteristics are proposed by Lerner et al. (2005) to lead to outcomes of Competence, Confidence, Character, Social Connectedness, and Compassion in youth participants. These outcomes are known as the " $5 \mathrm{Cs}$," reflecting positive youth outcomes that lead to successful adult development. 
Several studies have used this framework to focus on youth with COCI as a particular group of at-risk youth. A 2013 study found that the 5 Cs PYD model could be applied to youth with COCI (Maslow \& Chung). A few studies have examined outcomes associated with PYD programs for youth with $\mathrm{COCI}$ and found improvements in disease management, self-advocacy in the healthcare environment, leadership opportunities, and community membership (Chung, Burke, \& Goodman, 2010; Maslow et al., 2013; Maslow \& Chung, 2013; Maslow et al., 2016). However, these studies focused solely on clinical encounters or group mentoring programs and did not address broader programs meant to support and lead to positive outcomes for youth with COCI, such as camps or conferences.

\section{Current Study}

This study aimed to systematically review all the literature on camps for youth with COCI (specifically youth with physical conditions) since the mid-1900s, and assess the camp processes and psychosocial outcomes described using the PYD framework. This paper will provide a broad overview of findings from this unique dataset with specific considerations to camp demographics, the processes that align with PYD's Big 3, and outcomes that measured impacts on the $5 \mathrm{Cs}$, as described in the literature.

\section{Methods}

The systematic review was carried out using the PRISMA framework (Figure 1) (Moher, Liberati, Tetzlaff, Altman, \& PRISMA Group, 2009) in November, 2014. From PubMed, SCOPUS, Psycinfo, EMBASE, CINAHL and ERIC, 1292 titles were collected (after eliminating duplicates), without a date range restriction. From outside sources 46 additional titles were included, for a total of 1338 titles. From that total, 584 titles were eliminated, 288 abstracts were eliminated and 41 papers were eliminated based on strict exclusion and inclusion criteria at each level, leaving 425 total included studies (Figure 1). Exclusion criteria included:

- Certain article types: thesis, abstract or poster only, advertisement, directory, supply guidelines for camp, epidemiological reports of viral outbreaks at camps, non-English

- Certain camp types or restrictions: camps not intentionally designed for children with $\mathrm{COCl}$ or their families, obesity camps, camps lasting only 1 day (or less) or more than 3 months, camps exclusively for campers 7 years of age or younger or 22 years and older 
PYD at Camps for Youth with Chronic Illness

- Certain study types: medical observation studies measuring non-camp related variables, and studies assessing participant disease knowledge only; studies that tested new drugs or medical treatment modalities without descriptive specifics of camp implementation; studies that focused only on staff members' professional growth

Our original chronic illness search terms did not explicitly include mental illness or intellectual disability, however adding these terms to our exclusion criteria was deemed unnecessary, because no relevant articles were found.

Figure 1. PRISMA Framework

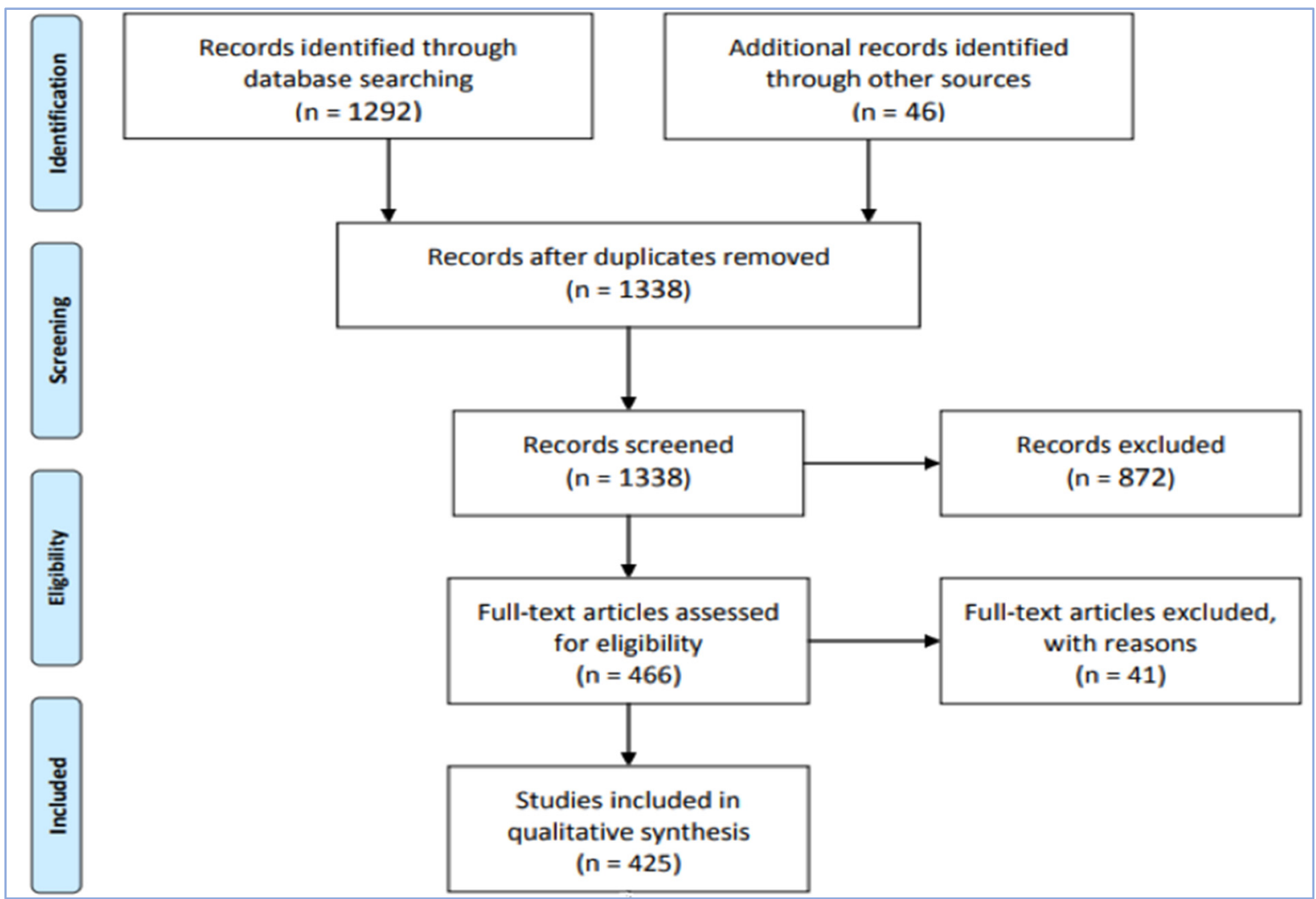

A data-housing tool was developed to collect data from the included studies at the manuscript level, and a codebook was made for coding the manuscripts using the qualitative software Atlas.ti. Data were collected from 425 manuscripts and then coded, with $10 \%$ coded by two trained coders until $90 \%$ inter-rater reliability was reached. The variables coded included the Big 3 characteristics of positive youth development programs (Lerner, 2004) (Table 1), and the 5 Cs of Positive Youth Development as defined by Lerner et al. (2005) (Table 2). 
The 425 studies reviewed did not intentionally measure the Big 3 features of positive youth development programs or the 5 Cs of positive youth development. However, the studies were coded to relate the camp practices that were described and the camp outcomes measured to the Big 3 characteristics of positive development programs and the $5 \mathrm{Cs}$, respectively. For example, outcome measurements such as increased independence, management of healthrelated self-care tasks, and social skills were coded as the Competence component of the 5 Cs. Additionally, a positive code for sustained relationships between youth and adults (Big 3 characteristic 1) was assigned if mentorship programming at camp was described.

Table 1. Definitions of the Big 3 Characteristics of Positive Youth Development Programs

\begin{tabular}{|l|l|}
\hline Characteristic & Definition \\
\hline 1. Sustained relationships & The program involves sustained relationships between youth and adults. \\
\hline 2. Skill-building & The program involves youth learning some form of life skill. \\
\hline 3. Youth leadership & The program involves youth actively in participation and/or leadership. \\
\hline
\end{tabular}

Table 2. Definitions of the 5 Cs of Positive Youth Development

\begin{tabular}{|l|l|}
\hline $\mathbf{5 C s}$ & Definition \\
\hline Character & Respecting rules, possessing behavioral standards, morality and integrity \\
\hline Competence & Positive views of one's social, academic, cognitive and vocational actions \\
\hline Caring & Sympathy and empathy for others \\
\hline Connection & $\begin{array}{l}\text { Positive bonds with peers, family, school, and community; reflected in mutually } \\
\text { contributory relationship. }\end{array}$ \\
\hline Confidence & Internalized overall positive self-worth and self-efficacy; global over domain specific \\
\hline
\end{tabular}

\section{Results}

Of the 425 studies reviewed, $36 \%$ included diabetes camps, $15 \%$ included camps with participants having a variety of illnesses (labeled "multiple illnesses"), $12 \%$ included cancer camps, and $11 \%$ included asthma camps. Table 3 displays the variety of illnesses addressed 
Journal of Youth Development | http://jyd.pitt.edu/ | Vol. 13 Issue 1-2 DOI 10.5195/jyd.2018.551

PYD at Camps for Youth with Chronic Illness

along with the total number of studies focusing on each one. It is important to note that a study was not necessarily directly proportional to a single camp. Several studies involved multiple camps, with each camp serving different medical conditions, and occasionally a single camp provided the research site for multiple studies.

Table 3. Number of Studies on Camps that Address Identified Conditions

\begin{tabular}{|l|l|}
\hline Type of Condition & Number of Studies (\%) \\
\hline Diabetes & $152(35.7)$ \\
\hline Multiple illnesses & $64(15)$ \\
\hline Other & $51(12)$ \\
\hline Cancer & $49(11.5)$ \\
\hline Asthma & $48(11.3)$ \\
\hline Burns & $21(5)$ \\
\hline Visual impairment & $9(2)$ \\
\hline Arthritis & $8(1.9)$ \\
\hline Cystic fibrosis & $6(1.4)$ \\
\hline Hearing impairment & $6(1.4)$ \\
\hline Skin disease & $4(0.9)$ \\
\hline Inflammatory bowel & $3(0.7)$ \\
\hline Seizure disorder & $3(0.7)$ \\
\hline Celiac disease & $2(0.5)$ \\
\hline
\end{tabular}


PYD at Camps for Youth with Chronic Illness

The total recorded number of camp participants in the studies reviewed was 28,402 . Many studies did not report the number of participants, so this number underestimates the total number of participants. The highest percentage of studies (44\%) recorded their oldest campers between the ages of 14 and 18, with 16 being the most common age cut-off. Overall, very few studies addressed campers in the transition between adolescence to young adulthood. Only $7 \%$ of studies in the sample addressed campers of any age above 18 , and just $5.5 \%$ of studies contained data on young adult participants between the ages of 19-24.

Figure 2 displays the number of studies found containing each of the three separate principles of Positive Youth Development programming. The largest percentage of studies (98\%) addressed the formation of supportive relationships at camp, while the second most commonly mentioned characteristic was active leadership at camp (94\%). The opportunity to learn life skills was the PYD measure addressed in the lowest percentage of studies (59\%). It is important to note that PYD principles were coded for camp programming, not study outcomes.

Figure 2. The Breakdown of Studies Containing Each Principle of PYD

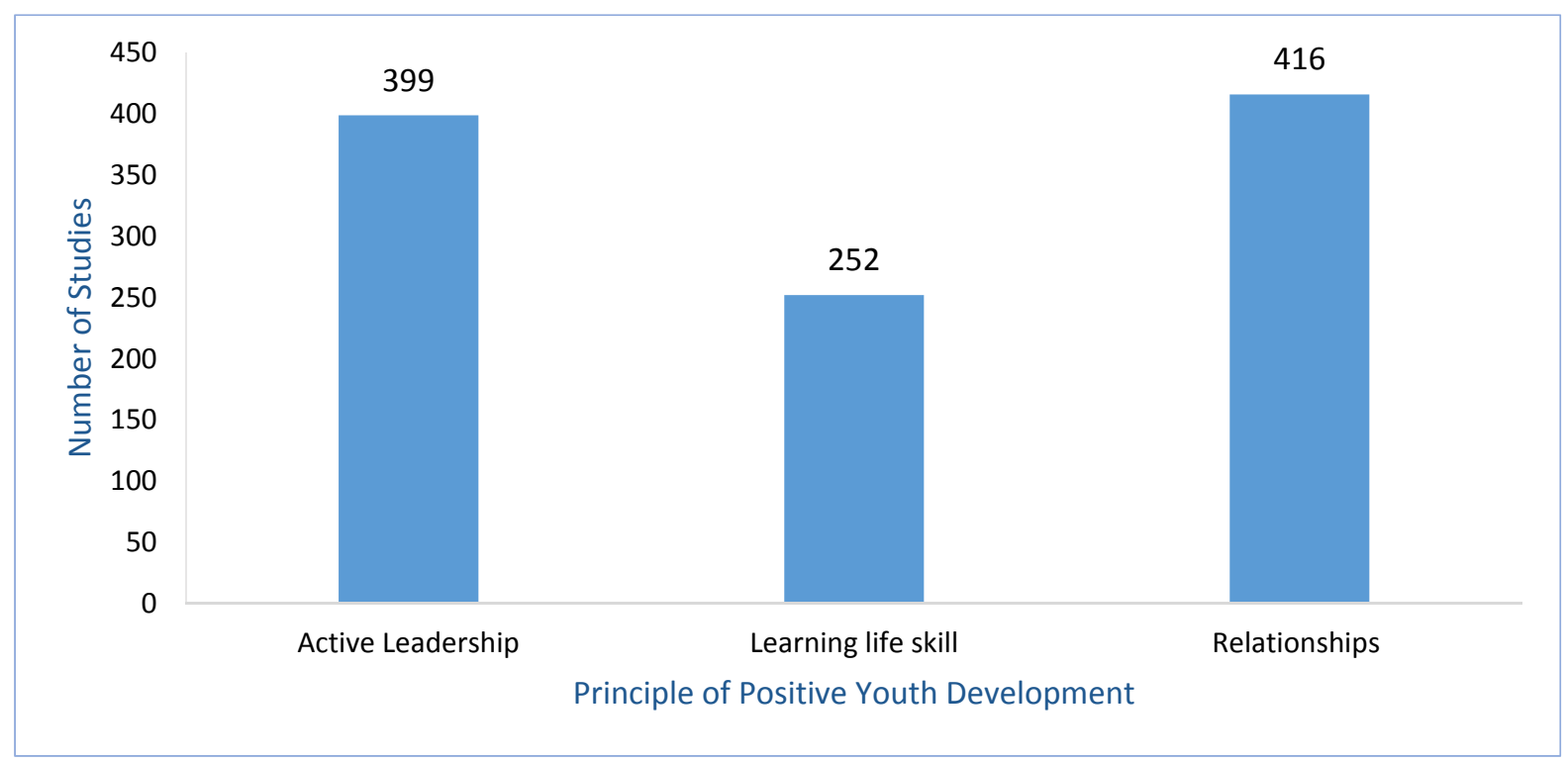

Figure 3 shows the number of studies in the sample that addressed specific combinations of PYD principles. Ninety-three percent of studies addressed the combination of leadership opportunities and the formation of sustained relationships at camp, while $56 \%$ of studies contained the combination of all three principles of PYD: leadership, life skills building, and formation of sustained relationships. 
Figure 3. Studies that Address Combinations of PYD Principles

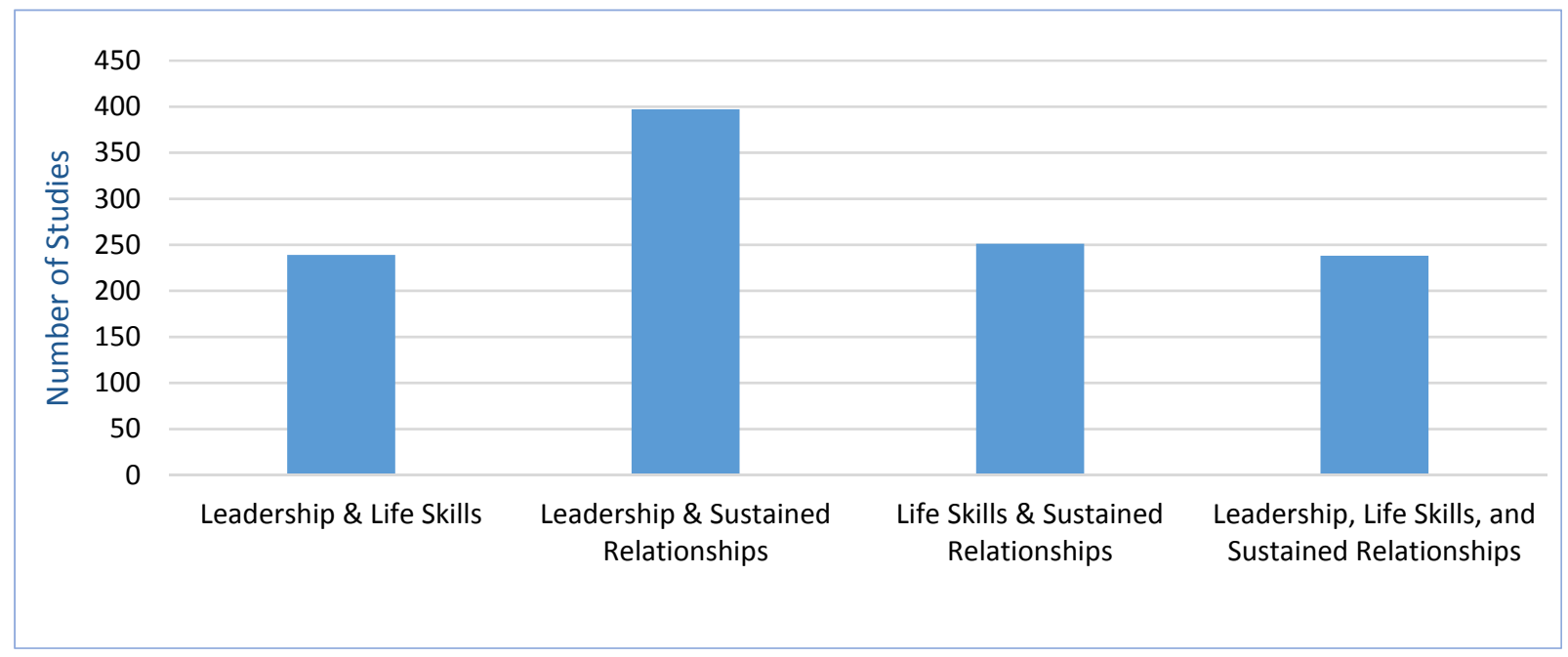

Figure 4 displays the number of studies in the sample that contained outcome evaluations of each individual element of the 5 Cs: Competence, Confidence, Connection, Character, and Caring/Compassion. Although the studies did not explicitly use the $5 \mathrm{Cs}$ framework, the outcome measures collected were tracked and coded using this framework. Forty-seven percent addressed outcomes related to Competence, 44\% addressed Confidence and 33\% addressed Connection in the reviewed studies. In contrast, only $4 \%$ of studies measured outcome variables related to Caring/Compassion, and only $2 \%$ of studies addressed outcomes related to Character.

Figure 4. The Number of Studies Containing Each 5 C Component

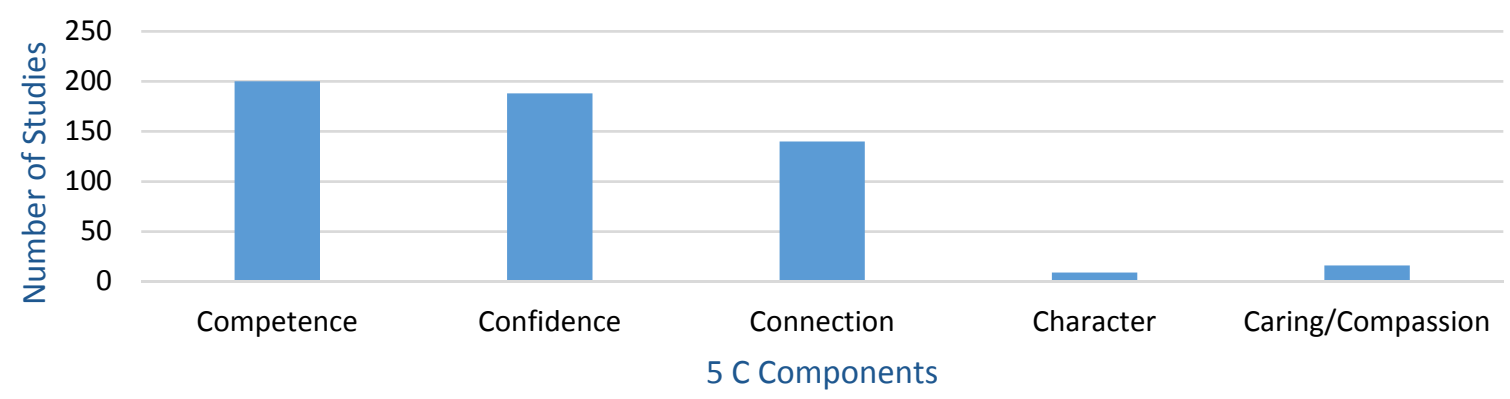


PYD at Camps for Youth with Chronic Illness

Figure 5 shows the number of studies in the sample that contained multiple $5 \mathrm{C}$ measures. Thirty percent of studies did not address variables related to any of the $5 \mathrm{C}$ components and an additional $30 \%$ mentioned outcomes pertaining to only one of the $5 \mathrm{C}$ components. Twenty-two percent of the studies addressed data related to two of the $5 \mathrm{C}$ components, $14 \%$ of studies mentioned outcomes concerning three of the $5 \mathrm{C}$ components, and $2 \%$ of studies addressed variables related to four of the $5 \mathrm{C}$ components. Less than $1 \%$ of studies ( 3 studies total) measured outcomes pertaining to all of the $5 \mathrm{C}$ components.

Figure 5. Number of Studies with Multiple 5 C Components

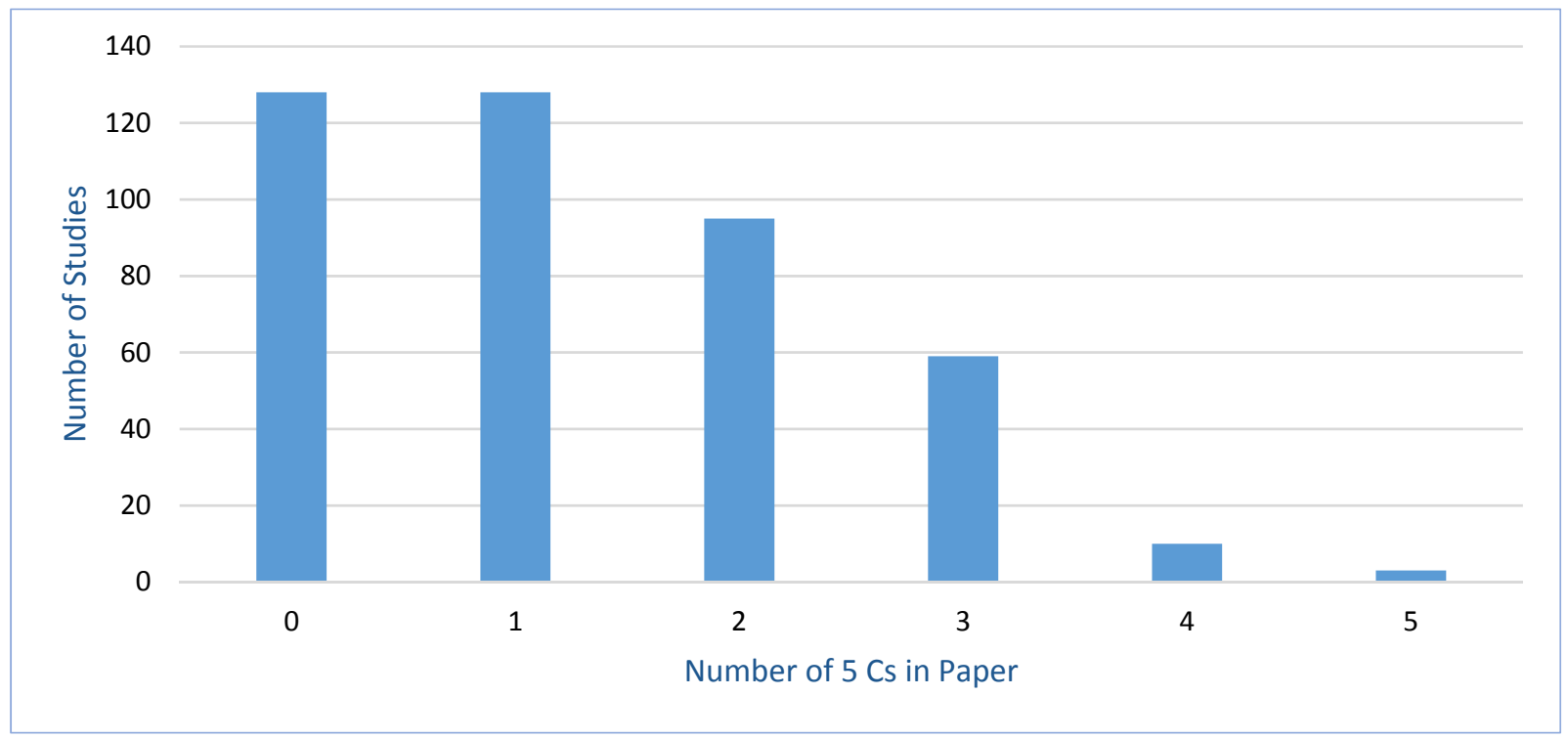

\section{Discussion}

The PYD framework fits well with the stated goals of camps for youth with physical childhood onset chronic illness (COCI) of helping youth adapt and thrive with their condition. While no study explicitly used the PYD approach, over 90 percent of studies described camps that deployed two of the three PYD principles (active leadership and sustained positive relationships). Over half of the studies described camps that had all three components of successful PYD programs. While the PYD framework was not used directly to shape these camps, such strong alignment with the activities occurring at camps suggests that a PYD approach to program design and program improvement is appropriate.

Camp programs have competing priorities and camp leadership often struggles to balance providing a fun experience for youth with a COCI with a desire to support adherence and 
PYD at Camps for Youth with Chronic Illness

improved medical self-care. Often these two factors, fun and skill-building, are seen as contradictory aims. The PYD framework and the application of the Big 3 components of PYD provide an opportunity to reframe this false dichotomy. Camp seems to be an ideal setting to develop skills since youth are situated in a context with supportive adults and opportunities for leadership. Harnessing the positive emotional attachment that youth with COCI have to camp to help them develop life-long skills is a natural extension of the mission of camping for youth with COCI.

\section{Implications for Practice: The Big 3}

We recommend using the Big 3 components of PYD programs as a framework for camp programming. First, we recommend creating opportunities for youth-adult sustained relationships by providing stable camp leadership year-to-year, encouraging returning staff to supervise the same group of youth over several years, and where appropriate, developing complementary yearlong programming for continued mentorship. Our second recommendation is to intentionally focus on skill-building at camp that develops individual life goals, self-care abilities, healthcare navigation tools, and wilderness or athletic skills, as examples. Finally, we suggest invo/ving youth actively in leadership through the development of camp programming such as by helping with the creation of camp rules, camp chants, activity planning and implementation, or maintaining camp facilities (e.g., cooking meals, cleaning cabins, prepping activity supplies, assisting with younger campers.)

In addition to the "Big 3" of PYD (Lerner, 2004), the Institute of Medicine outlined eight aspects of youth programs that support PYD and are useful for the development of camp programming: physical and psychological safety, appropriate structure, supportive relationships, opportunities to belong, positive social norms, support for efficacy and mattering, opportunities for skill building, and the integration of family, school, and community efforts (Eccles \& Gootman, 2002). With these two approaches, camps for youth with COCI can address varied developmental needs through their camp programs.

\section{Implications for Practice: Counselors as Leaders}

In addition to programming for young camp participants, counselors at camp currently represent a missed opportunity for implementing the PYD framework. The vast majority of participants who attended the camps described in this study were younger than 16. The camps served youth under 16 and did not focus on the transition to adulthood and adult responsibility. 
PYD at Camps for Youth with Chronic Illness

Given the various struggles of adolescents and young adults with COCI (Newacheck et al., 1998; Van Dyck, Kogan, McPherson, Weissman, \& Newacheck, 2004), this lack of focus on transition seems to be a missed opportunity. Camps for youth with COCI have already established the supportive mentoring relationships with youth to promote their positive development, but the relationship ends just when youth are most in need of this connection and support. An opportunity exists for camp programs to expand their reach to serve young adults. Diabetes camps provide an example of the missed opportunity, as over 1700 young adults with diabetes serve as counselors at diabetes camps each year but are not typically a focus of the camp programming. We recommend camps for children with COCI incorporate camp graduates into leadership and develop programming to help their young adult counselors with COCI learn leadership skills.

Camp counselors should have decision-making power in the development of camp programming and need to be provided with explicit training in creating a safe environment for campers to thrive. Young adult counselors need to be provided with training in aspects that support positive development in their campers such as group facilitation, conflict resolution, and creating emotionally safe spaces, in addition to training in traditional skills such as CPR, wilderness safety, and camp programming. Counselors could also be matched with camp leadership for sustained mentorship.

\section{Implications for Practice: The 5 CS}

The majority of studies examined one or more of the PYD elements from the 5 Cs model. It is striking how few studies included assessment of character development or compassion as intentional outcomes. This fact is particularly notable since anecdotally camp programs often seek to address these two attributes. One reason for the disconnect between stated goals and measured outcomes may be related to the way in which many camp programs developed separate from a specific theoretical grounding. The PYD framework can serve as a theoretical grounding for assessment of camp programs for youth with COCI. This framework would allow camp researchers to more broadly evaluate the outcomes of camp participation including examining all 5 Cs (only 3 studies identified in this study incorporated all $5 \mathrm{Cs}$ in their outcome evaluation).

Additionally, measurement consistency across camp studies is needed for future study, so that outcomes can be compared across programs. Thus far, illness-specific camp studies have utilized a wide range of assessment methods and tools, making it difficult to compare results. 


\section{PYD at Camps for Youth with Chronic Illness}

The PYD framework is one approach that can be standardized across illness-specific camp studies for adolescents and young adults with COCI and shows promise for evaluating important psychosocial outcomes. For example, future studies could utilize the Positive Youth Development Inventory-Short form to measure the impact of camp on youth development (Arnold, Nott, \& Meinhold, 2012).

\section{Limitations}

This study is limited by the type of analysis conducted, as well as by the available data. The method used to assess PYD components was abstracted from the text of each study, as the studies did not use this framework in their design. In addition, the assignment of outcome category was determined by post-hoc coding based on the definition of each of the PYD components. This study is purely descriptive and did not look at whether having more PYD elements in program design was linked to positive outcomes. Despite these limitations, this report is likely the most comprehensive summary of medical specialty summer camp studies focused on youth with COCI.

\section{Summary}

Thousands of children with a wide range of physical childhood-onset chronic illnesses attend illness-specific camps each year. Studies of youth at illness-specific summer camps have been published for almost 70 years and the number of camps and related studies is increasing. This comprehensive study used the PYD framework to examine the stated activities of each camp and the measured outcomes of each study to provide important information to guide camp program leaders, as well as researchers interested in evaluating such camps using a PYD approach in the future. The value of this type of analysis is that it highlights opportunities for camps to align their programming with the PYD framework, such as by more explicitly targeting life-skill development, which ultimately may improve positive outcomes for youth with COCI.

\section{References}

Arnold, M. E., Nott, B. D., \& Meinhold, J. L. (2012). The positive youth development inventory short version. Corvallis: Oregon State University 4-H Youth Development Program. Retrieved from Oregan State University website: http://oregon.4h.oregonstate.edu/about/pre/instruments/pyd

Chung, R. J., Burke, P. J., \& Goodman, E. (2010). Firm foundations: strength-based approaches to adolescent chronic disease. Current opinion in pediatrics, 22(4), 389-397. 
Journal of Youth Development | http://jyd.pitt.edu/ | Vol. 13 Issue 1-2 DOI 10.5195/jyd.2018.551

PYD at Camps for Youth with Chronic Illness

Eccles, J., \& Gootman, J. (2002). Community programs to promote youth development. Washington DC: National Academy Press.

Epstein, I., Stinson, J., \& Stevens, B. (2005). The effects of camp on health-related quality of life in children with chronic illnesses: a review of the literature. Journal of Pediatric Oncology Nursing, 22(2), 89-103.

Lerner, R. M. (2004). Liberty: Thriving and civic engagement among America's youth: Sage.

Lerner, R. M., Abo-Zena, M., Bebiroglu, N., Brittain, A., Doyle Lynch, A., \& Issac, S. (2009). Positive youth development: Contemporary theoretical perspectives. In R. J. DiClemente, J. S. Santelli, \& R. A. Crosby (Eds.), Adolescent health: Understanding and preventing risk behaviors. San Francisco, CA: Jossey-Bass.

Lerner, R. M., Lerner, J. V., Almerigi, J. B., Theokas, C., Phelps, E., Gestsdottir, S., . . Ma, L. (2005). Positive youth development, participation in community youth development programs, and community contributions of fifth-grade adolescents: Findings from the first wave of the 4-H study of positive youth development. The Journal of Early Adolescence, 25(1), 17-71.

Maslow, G., Adams, C., Willis, M., Neukirch, J., Herts, K., Froehlich, W., . . Rickerby, M. (2013). An evaluation of a positive youth development program for adolescents with chronic illness. Journal of Adolescent Health, 52(2), 179-185.

Maslow, G., \& Chung, R. J. (2013). Systematic review of positive youth development programs for adolescents with chronic illness. Pediatrics, 131(5). 2012-1615.

Maslow, G., Hill, S., Rozycki, A., Sadun, R., Sendowski, M., \& Neukirch, J. (2016). Character development pilot evaluation of two programs for youth with chronic illness. Journal of Youth Development, $10(3), 115-126$.

Maslow, G., \& Lobato, D. (2009). Diabetes summer camps: history, safety, and outcomes. Pediatric diabetes, 10(4), 278-288.

Maslow, G., \& Lobato, D. (2010). Summer camps for children with burn injuries: a literature review. Journal of Burn Care \& Research, 31(5), 740-749.

McAuliffe-Fogarty, A. H., Ramsing, R., \& Hill, E. (2007). Medical specialty camps for youth with diabetes. Child and adolescent psychiatric clinics of North America, 16(4), 887-908.

Moher, D., Liberati, A., Tetzlaff, J., Altman, D. G., \& The PRISMA Group. (2009). Preferred reporting items for systematic reviews and meta-analyses: the PRISMA statement. PLoS Medicine, 6(7): e1000097.

Moola, F., Faulkner, G., White, L., \& Kirsh, J. (2014). The psychological and social impact of camp for children with chronic illnesses: a systematic review update. Child: Care, Health and Development, $40(5), 615-631$. 
Journal of Youth Development | http://jyd.pitt.edu/ | Vol. 13 Issue 1-2 DOI 10.5195/jyd.2018.551 PYD at Camps for Youth with Chronic Illness

Newacheck, P. W., Strickland, B., Shonkoff, J. P., Perrin, J. M., McPherson, M., McManus, M., . . Arango, P. (1998). An epidemiologic profile of children with special health care needs. Pediatrics, 102(1), 117-123.

Ramsing, R. (2007). Organized camping: A historical perspective. Child and Adolescent Psychiatric Clinics of North America, 16(4), 751-754.

Van Dyck, P. C., Kogan, M. D., McPherson, M. G., Weissman, G. R., \& Newacheck, P. W. (2004). Prevalence and characteristics of children with special health care needs. Archives of Pediatrics $\&$ Adolescent Medicine, 158(9), 884-890. 